\title{
AN EVALUATION OF IMMUNOFLUORESCENCE ASSAYS ON ASEXUAL BLOOD STAGES OF PLASMODIUM FALCIPARUM AND PLASMODIUM VIVAX FOR QUANTITATING ANTIBODIES IN ENDEMIC AREA POPULATIONS
}

\author{
KOSALA NAGENDRAN ${ }^{1,2}$, MANTHRI S. RAMASAMY ${ }^{1}$ and R. RAMASAMY 1 \\ 1 Division of Life Sciences, Institute of Fundamental Studies, Hantana Road, \\ Kandy. \\ 2 Department of Parasitology, Faculty of Medicine, University of Jaffna, Jaffna.
}

(Received : 30 November 1994; accepted : 16 February 1995)

\begin{abstract}
Antibodies against asexual blood stage antigens were measured by immunofluorescence assay (IFA) in sera collected in February 1990 and May 1990 from Weheragala village in the Mahaweli irrigation project located in the dry zone of Sri Lanka. The results were compared with IFA on sera collected in October 1990 at Nikawehera village in the intermediate rainfall zone of Sri Lanka. The IFA titres in Weheragala sera were also compared with antibody concentrations against specific epitopes of $P$. falciparum and $P$. vivax surface antigens previously measured by an immunoradiometric assay (IRMA) on the same serum samples. At both Nikawehera and Weheragala, IFA titres were greater in adults than in 7-15y old children, IFA titres against $P$. falciparum and $P$. vivax were significantly correlated at both locations. IFA titres are also a less sensitive index of malaria transmission than specific antibody concentrations measured by IRMA.
\end{abstract}

Key words: Antibodies, epidemiology, immunofluorescence, immunoradiometric assay, malaria, Plasmodium falciparum, Plasmodium vivax.

\section{INTRODUCTION}

The Mahaweli irrigation project is a large agricultural development project in the dry zone of Sri Lanka that has produced ecological changes which have had an impact on mosquito borne diseases. ${ }^{1,2}$ The dry zone receives maximum rainfall during the northeast (NE) monsoon (November-January) and little or no rain during the rest of the year. Malaria is endemic in the dry zone with peak transmission occurring during the NE monsoon season. Plasmodium falciparum and $P$. vivax are common parasites in the Mahaweli project zone. Details of malaria transmission in Weheragala, a village in the Mahaweli irrigation project have been described. ${ }^{1}$ Antibodies against repetitive epitopes on $P$. falciparum and $P$. vivax circumsporozoite proteins and two epitopes on each of the $185 \mathrm{kDa}$ and $45 \mathrm{kDa} P$. falciparum merozoite surface proteins (termed PMMSA and GYMSSA respectively) were measured by immunoradiometric assay (IRMA) at Weheragala. ${ }^{3}$ A significant proportion of the population at Weheragala possessed antibodies directed against the epitopes. Seasonal variations in antibody levels that were related to malaria transmission rates were obsserved at Weheragala. ${ }^{3}$ We report here on the measurement of antibodies to asexual blood stages of $P$. falciparum

Abbreviations: CS-circumsporozoite, ELISA-enzyme linked immunosorbent assay, GYMSSAglycosylated and myristilated smaller surface antigen, IFA-immunofluorescence assay, IRMAimmunoradiometric assay, PMMSA-precursor to the major merozoite surface antigens, PBS phosphate buffered saline. 
and $P$. vivax by an immunofluorescence assay (IFA) using the same serum samples from Weheragala that were utilised for IRMA. The sera were collected in February 1990 at the end of the main transmission season and three months later in May 1990, during the low transmission season.,3 IFA has been widely used for detecting, but not necessarily,quantitating, malaria antibodies in many endemic countries. ${ }^{4,5}$ However IRMA ${ }^{3,5,6}$ and the closely related enzyme linked immunosorbent assay (ELISA) ${ }^{4,7,8}$ that utilise synthetic peptide or recombinant proteins as targets, are increasingly used for this purpose. Since there is little detailed information on the comparison between IFA and IRMA in epidemiological studies of malaria, we determined whether (a) the antibody titres measured by IFA varied with malaria transmission rates, (b) the IFA titres related to parasitaemia, (c) a relationship existed between IFA titres and the age of individuals and (d) anti- $P$. falciparum and anti- $P$. vivax titres determined by IFA were correlated. We also compare IFA antibody titres with antibody levels against epitopes on merozoite and sporozoite surface antigens that were previously measured by IRMA using the same sera. ${ }^{3}$ The IFA results obtained at Weheragala are further compared with IFA titres observed in sera collected in October 1990 from Nikawehera village, located in the intermediate rainfall zone of Sri Lanka and $70 \mathrm{~km}$ from Weheragala. ${ }^{9,10}$ The intermediate rainfall zone receives some rain from the southwest monsoon (May-July) in addition to that from the NE monsoon. Malaria transmission in the intermediate zone is closely related to rainfall and is relatively unstable..$^{9,10}$

\section{METHODS AND MATERIALS}

\section{Study population and serum samples}

The main population cohort chosen for this study were selected randomly in February 1990 from a cadju plantation. in Weheragala, which is located in System B of the Mahaweli irrigation project. ${ }^{1,3}$ Records from the Aralaganwila rural hospital, close to the study area, showed a high prevalence of malaria in the area for several years. ${ }^{1}$ Before the blood collection, informed consent was obtained from each person and from parents in the case of children. Venous blood samples collected aseptically by venupuncture in February and May 1990 from 123 and 75 persons of the same cohort respectively, were used in the IFA. Serum was separated and stored at $-20^{\circ} \mathrm{C}$ until use. The proportions of sera from males were $43.1 \%$ and $36.5 \%$ in February and May respectively. Sera from children aged 7-15y comprised, $30 \%$ and $27 \%$ of the samples in February and May 1990 respectively. Thin and thick blood films were also made at the time of blood collection, stained with Giemsa, and examined for malaria parasites.

Nikawehera is a long established farming village in the Matale district located in the intermediate rainfall zone of Sri Lanka.,10 Details of malaria incidence and transmission characteristics at Nikawehera and the collection of sera from a randomly selected cohort were previously described.9.10 Sera collected from 54 adults and 27 children aged 7-15y in October 1990 were analysed by IFA for comparison with the sera from Weheragala. 


\section{Immunoradiometric assay (IRMA)}

Methodology, details of target antigens and results of the IRMA on the sera that measured antibodies to $P$. falciparum and $P$. vivax circumsporozoite (CS) repeats and $P$. falciparum merozoite surface proteins were reported previously. ${ }^{3}$ Antigens used in IRMA were $R_{32}$ tet32 (recombinant protein containing $P$. falciparum CS protein repeats), Pv210 capture antigen (recombinant protein containing the major $P$. vivax CS protein repeats), $\operatorname{Pv}(247)_{3}$ (a synthetic peptide containing three repeats of the variant $P$. vivax CS protein coupled to boiled casein) and the synthetic peptides P102 (TAADTPTATESISPSPPC) and P103 (RNNHPQNTSDSQKECTDGNK) derived from variable region and the conserved C-terminus respectively of GYMSSA and peptides P109 (VTHESYQELVKKLEALEDAC) and P110 (IENEYEVLYLKPLAGVYRSLKC) derived from the conserved $\mathrm{N}$ and $\mathrm{C}$ terminii respectively of PMMSA. ${ }^{3}$

\section{Immunofluorescence assay}

Immunofluorescence assay was carried out to detect antibody titres to blood stages of $P$. falciparum and $P$. vivax using standard procedures. ${ }^{11} P$. falciparum asexual stages were obtained from a culture of $P$. falciparum FCA 20/GHA strain, maintained at the Institute of Tropical Medicine, Antwerp. $P$. vivax asexual stages were obtained from $P$. vivax infected blood samples from patients in Sri Lanka. Blood cells were washed three times with PBS (pH 7.2), diluted further in the same buffer and 10 drops of foetal calf serum added to every $\mathrm{ml}$ of the cell suspension. A cell dilution providing $10-15$ parasites per microscopic field was used to spot teflon coated multispot slides (Wellcome, Belgium). The slides were air dried and stored at $-20^{\circ} \mathrm{C}$ until use.

Serial dilutions of human sera were made in $\operatorname{PBS}(1: 20,1: 80,1: 160,1: 320$, $1: 640$ ). In order to limit IFA tests to a manageable number, dilutions of sera greater than 1:640 were not used. Diluted human serum was added to the blood film and incubated for $30 \mathrm{~min}$ at room temperature in a moist box. After the incubation the slides were washed twice, for $10 \mathrm{~min}$ each in PBS. Washed slides were incubated with fluorescein conjugated goat anti-human Ig (with specificity for human heavy and light immunoglobulin chains) at a dilution of 1:100 in PBS containing Evans blue 1:10,000 as counterstain and allowed to react for $30 \mathrm{~min}$ at room temperature. Slides were washed twice with PBS, for $10 \mathrm{~min}$ each and dried. The slides were covered with glycerol and a coverslip. Reading was carried out using a Leitz Ortholux fluorescence microscope. The titre was defined as the greatest dilution of serum giving a positive IFA.

\section{Data analyses}

All the statistical analyses were performed using the SAS/STAT package (SAS Institute, Cary, NC, USA). Since IFA antibody titres were not normally distributed, the titres were transformed into logarithmic values where necessary with a negative IFA being ascribed the value zero i.e. log value of unity. Details of the individual tests performed are described in the relevant text and table legends. 


\section{RESULTS}

\section{Proportion of IFA positive sera}

Positive antibody response in IFA were seen in a significant proportion of the Weheragala population. There was no significant difference in the proportions responding in February and May to both $P$. falciparum and $P$. vivax. The prevalence of antibodies to $P$. falciparum was greater than against $P$. vivax, noticeably in children (Table 1). The proportions of children and adults with antibodies were 0.81 and 0.83 respectively against both $P$. falciparum and $P$. vivax at Nikawehera in October 1990.

Table 1: Proportions of IFA positive sera at Weheragala.

\begin{tabular}{lllllll}
\hline & \multicolumn{2}{c}{ P. falciparum } & \multicolumn{4}{c}{ P. vivax } \\
& Feb 90 & May 90 & p & Feb 90 & May 90 & p \\
\hline Children & 0.84 & 0.80 & n.s & 0.49 & 0.50 & n.s \\
& $31 / 37$ & $16 / 20$ & & $18 / 37$ & $10 / 20$ & \\
Adults & 0.80 & 0.82 & n.s & 0.76 & 0.71 & n.s \\
& $69 / 86$ & $45 / 55$ & & $65 / 86$ & $39 / 55$ & \\
\hline
\end{tabular}

Significance of differences between the proportions were examined by the chi square test. Degree of freedom $=1$. n.s. = not significant $(p>0.05)$.

\section{Mean antibody levels}

Although the IFA titres were slightly greater in May, there were no detectable differences in titres between February and May 1990 for both P. falciparum and $P$. vivax at Weheragala (Table 2). Comparable logarithmic mean antibody titres observed at Nikawehera were -1.85 against $P$. falciparum and -1.63 against $P$. vivax in October 90.

Table 2: Logarithmic mean of IFA antibody titres at Weheragala.

\begin{tabular}{lcccc}
\hline & Feb 90 & May 90 & $\mathrm{Z}$ & $\mathrm{p}$ \\
\hline P. falciparum & $-1.74 \pm 0.97$ & $\begin{array}{c}-1.84 \pm 0.89 \\
(0.02)\end{array}$ & -0.04 & n.s. \\
& & & & \\
P. vivax & $-1.21 \pm 0.93$ & $\begin{array}{c}-1.21 \pm 1.00 \\
(0.06)\end{array}$ & -0.11 & n.s \\
& $(0.06)$ & & \\
\hline
\end{tabular}

Significance of differences between the February and May IFA titres were examined by the nonparametric Wilcoxon sum of ranks test. Values given are logarithmic titres $\pm \log$ standard deviation. The antilog of the logarithmic mean titres are given in parentheses. n.s. $=$ not significant $(p>0.05)$. 


\section{Relationship between IFA titres and concomitant blood infection}

$P$. falciparum blood film positive individuals had higher antibody titres than uninfected persons at Weheragala. No statistical significance could be ascribed to this difference, including May 90 where only one $P$. falciparum parasitaemic person was detected in the study group. $P$. vivax parasitaemic persons had slightly lower antibody titres than non-parasitaemic persons (Table 3). A similar analysis was not done for the data from Nikawehera.

Table 3: Relationship between active infection and IFA antibody titres at Weheragala.

\begin{tabular}{cccc}
\hline & \multicolumn{2}{c}{$P$. falciparum } & \\
& Parasitaemic & Non-parasitaemic & \\
Feb 90 & $-1.77 \pm 1.05$ & $-1.74 \pm 0.96$ & n.s. \\
May 90 & $(0.02)$ & $(0.02)$ & \\
& -2.81 & $-1.83 \pm 0.89$ & n.s. \\
& $(0.002)$ & $(0.01)$ & \\
& & & \\
Feb 90 & Parasitaemic vivax & Non-parasitaemic & \\
& & & \\
May 90 & $-0.88 \pm 0.93$ & $-1.24 \pm 0.93$ & n.s \\
& $(0.13)$ & $(0.06)$ & n.s \\
& $-0.94 \pm 1.32$ & $-1.22 \pm 1.00$ & \\
\hline
\end{tabular}

Significance of differences between means were determined by the Student's t test on logarithmically transformed values of IFA titres. Values given are mean logarithmic titres $\pm \log$ standard deviation. The antilog of the log mean titres are given in parentheses. $P$. falciparum February $N=14+v e$ and 109-ve; May $\mathrm{N}=1+$ ve and 74-ve. $P$. vivax February $\mathrm{N}=8+$ ve and 115 -ve ; May $\mathrm{N}=3+$ ve and 72 -ve. n.s. $=$ not significant $(\mathbf{p}>0.05)$.

\section{IFA titres in adults and children}

Adult antibody titres to both $P$. falciparum and $P$. vivax, were higher than in children at Weheragala (Table 4). At Nikawehera, adults had higher mean log IFA titres against both $P$. falciparum ( -1.91 adults vs -1.71 children) and $P$. vivax $(-1.75$ adults vs -1.38 children), although the differences were not statistically significant.

\section{Correlation of antibody titres}

The relationship between IFA titres to $P$. falciparum and $P$. vivax within individuals was examined by Spearman's rank correlation analysis. The results showed that there was a highly significant correlation in both February $(\mathrm{N}=123$, $\mathrm{r}=0.42, \mathrm{p}<0.0001)$ and $\mathrm{May}(\mathrm{N}=75, \mathrm{r}=0.47, \mathrm{p}<0.0001)$, between the $P$. falciparum and $P$. vivax antibody titres measured by blood stage IFA. Similar significant correlations between the $P$. falciparum and $P$. vivax IFA titres were seen at. Nikawehera $(\mathrm{N}=81, \mathrm{r}=0.52, \mathrm{p}<0.0001)$. 
Table 4: Comparison of logarithmic mean IFA antibody titres in adults and children at Weheragala.

\begin{tabular}{|c|c|c|c|c|c|c|}
\hline & \multicolumn{3}{|c|}{ P. falciparum } & \multicolumn{3}{|c|}{ P. vivax } \\
\hline & adults & children & $\mathbf{p}$ & adults & children & p \\
\hline Feb 90 & $\begin{array}{c}-1.81 \pm 1.01 \\
(0.02)\end{array}$ & $\begin{array}{c}-1.59 \pm 0.83 \\
(0.03)\end{array}$ & n.s & $\begin{array}{c}-1.37 \pm 0.89 \\
(0.04)\end{array}$ & $\begin{array}{c}-0.84 \pm 0.92 \\
(0.15)\end{array}$ & $<0.01$ \\
\hline May 90 & $\begin{array}{c}-2.01 \pm 0.88 \\
(0.01)\end{array}$ & $\begin{array}{c}-1.38 \pm 0.08 \\
(0.04)\end{array}$ & $<0.01$ & $\begin{array}{c}-1.35 \pm 1.03 \\
(0.04)\end{array}$ & $\begin{array}{c}-0.85 \pm 0.88 \\
(0.14)\end{array}$ & n.s \\
\hline
\end{tabular}

Significance of differences between means were determined by the Student's $t$ test on logarithmically transformed values of IFA titres. Values given are mean logarithmic titres $\pm \log$ standard deviation. The antilog of the logarithmic mean titres are given in parentheses. February: adults $=86$, children $=$ 37. May: adults $=55$, children $=20$. n.8. $=$ not significant $(p>0.05)$.

\section{Correlation between IFA titres and antibody levels to different epitopes measured by IRMA}

The relationship between $P$. falciparum IFA titres and cpm in IRMA against the $P$. falciparum CS repeat and P102, P103, P109 and P110 as well as those between $P$. vivat IFA titres and cpm in IRMA against the $P$. vivax and variant $P$. vivax CS repeats were examined by Spearman's rank correlation test for the February and May data at Weheragala. Significant correlations were only observed between the $P$. vivax IFA titres and IRMA antibody levels against the variant $P$. vivax CS repeat in February $1990(\mathrm{r}=-0.18, \mathrm{p}<0.05)$ and between the $P$. vivax IFA titre and IRMA antibody levels against the major $P$. vivax CS repeat in May $1990(\mathrm{r}=-0.31$, p 0.01 ). A similar comparison of IRMA antibody levels at Nikawehera ${ }^{12}$ and IFA titres in the October 1990 sera was also done. The results showed that the $P$. falciparum IFA titre was significantly associated only with antibodies to the $P$. falciparum CS repeat $(\mathrm{r}=-0.36, \mathrm{p}<0.001)$ and the $P$. vivax IFA titre was significantly associated with antibodies to the $P$. vivax $\operatorname{CS}$ repeat $(\mathrm{r}=-0.42, \mathrm{p}<0.0001)$. The negative values for the correlation coefficient $r$, is due to the titres being expressed as reciprocals.

\section{DISCUSSION}

Estimating antibody concentration by measuring IFA antibody titres involves testing serial dilutions of sera. This is one of the disadvantages of IFA compared to IRMA. In IRMA, antibody concentrations can be estimated by using different sera at a standard dilution. ${ }^{3}$ The number of dilutions used in the present investigation was limited to provide a manageable number of IFA tests. This tends to reduce the power of the statistical analyses involving antibody titres but does not obviate the main conclusions reached in the study.

The prevalence of antibodies against $P$. falciparum and $P$. vivax at Weheragala determined by IFA was a little lower than that determined by IRMA against CS repeats $^{3}$ (0.97 and 0.83 in February 1990 and May 1990 respectively for 
the $P$. falciparum CS repeat, 0.87 and 0.62 in February 1990 and May 1990 respectively for the $P$. vivax CS repeat). However the prevalence of antibodies against $P$. falciparum by IFA was considerably greater than that detected by IRMA against the merozoite surface protein epitopes P102, P103, P109. or P110 (varying from 0.24 to 0.67$)^{3}$ Anti-P. falciparum antibody prevalences at Nikawehera and Weheragala were comparable by IFA but $P$. vivax antibodies were more prevalent at Nikawehera than at Weheragala. The results suggest that IRMA against CS repeats and asexual blood stage IFA are about equally useful for determining exposure to malaria in a population.

The IFA titres to asexual stages did not show significant seasonal variation at Weheragala. We reported previously that antibody levels against the CS repeats of $P$. falciparum and $P$. vivax determined by IRMA fell significantly from February to May 1990 at Weheragala. ${ }^{3}$ Similar falls in antibody levels against the four epitopes on the $P$. falciparum merozoite surface antigens were also seen, but these were not always large enough to be statistically significant. ${ }^{3}$ It was suggested that this may arise because blood stage infections persist at subclinical levels in the populations long after the drop in sporozoite inoculation rates. Together with the fact that the IFA measured antibodies against a large number of antigens on asexual stages, this may explain the similarities in the February and May IFA titres. Antibody titres determined by IFA are therefore less useful than IRMA against CS repeats for measuring changes in malaria transmission that occur in the order of a few months. This conclusion was also reached in an investigation carried out in Thailand. ${ }^{8}$

Adults always had higher IFA antibody titres than children to $P$. vivax and $P$. falciparum at both Nikawehera and Weheragala. This probably is due to cumulative immunological memory and the production of some long-lived antibodies after each malaria episode $:^{3-8}$

No significant correlation was found between the presence of blood stage infection and IFA antibody titres at Weheragala. Similar observations were made previously with IRMA. ${ }^{3}$ This may be partly due to the small numbers of parasitaemic individuals observed in the study. Rapid access to medical treatment available to persons in Weheragala ${ }^{13}$ coupled with high sporozoite inoculation rates, ${ }^{1}$ may also contribute to reducing differences in antibody titres between parasitaemic and non-parasitaemic individuals.

Previously significant associations were observed in some instances between the antibody responses to the epitopes on merozoite surface proteins on one hand and antibodies to the $P$. falciparum CS repeat on the other by IRMA. ${ }^{3}$ A similar relationship between total antibodies against blood stages measured by IFA and antibodies against the CS repeats measured by IRMA were seen in some, but not all, instances in the present investigation. Interestingly, IFA antibody titres to blood stages did not correlate with antibody responses to specific GYMSSA and PMMSA epitopes. This suggests that antibodies against other epitopes, probably on different asexual stage antigens, ${ }^{14}$ predominantly influence the IFA. 
We have previously observed that antibody levels measured by IRMA against the $P$. falciparum and $P$. vivax CS repeats were significantly associated although antibodies against the two CS repeats do not cross-react. ${ }^{3,12}$ It was suggested that the risks of contracting $P$. falciparum and $P$. vivax malaria are therefore significantly related at both locations in Sri Lanka, e.g. factors such as the major vector species involved, appear to be the same for the two types of malaria. However antibodies against whole asexual blood stages of $P$. falciparum and $P$. vivax will detect many potentially cross-reactive antigens present in the two species. The PMMSA molecules in $P$. falciparum and $P$. vivax, for example, have shared sequences that can give rise to cross-reactive antibodies. ${ }^{15}$ Hence the significance of the correlations seen in the IFA titres against asexual blood stage parasites of $P$. vivax and $P$. falciparum are more difficult to interpret than the correlations seen by IRMA against specific epitopes.

\section{Acknowledgement}

This work was supported in part by the Belgian Agency for Development Cooperation and the International Atomic Energy Agency. We thank Prof. M. Wery, Institute of Tropical Medicine, Antwerp for the IFA tests done in his laboratory.

\section{References}

1. Ramasamy R., De Alwis R., Wijesundera A. \& Ramasamy M.S. (1992). Malaria transmission at a new irrigation project in Sri Lanka. The emergence of Anopheles annularis as a major vector. American Journal of Tropical Medicine and Hygiene 47: 547-553.

2. Amerasinghe F.P. \& Ariyasena T.G. (1990). Larval survey of fresh water breeding mosquitoes during irrigation development in the Mahaweli project, Sri Lanka. Journal of Medical Entomology 21: 789-802.

3. Ramasamy R., Nagendran K. \& Ramasamy M.S. (1994). Antibodies to epitopes on merozoite and sporozoite surface antigens as serological markers of malaria transmission - studies at a site in the dry zone of Sri Lanka. American Journal of Tropical Medicine and Hygiene 50: 537-547.

4. Chizzoloni C., Delaporte E., Kaufman M.H., Akue J.P., Verdin A.S., Pessi A. \& Del Giudice G. (1989). Age related prevalence of antibody response against three different, defined Plasmodium falciparum antigens in children from Haut-Ogooue province in Gabon. Transactions of the Royal Society for Tropical Medicine and Hygiene 83: 147-151.

5. Marsh K., Hayes R.H., Carson D.C., Oto L., Shenton F., Byass P., Zavala F. \& Greenwood B.M. (1988). Anti-sporozoite antibodies and immunity to malaria in a rural Gambian population. Transactions of the Royal Society for Tropical Medicine and Hygiene 82: 532-537. 
6. Esposito F., Lombardi S., Modiano D., Zavala F., Reeme J., Laminzana L., Coluzzi M. \& Nussenzweig R.S. (1988). Prevalence and levels of antibodies to the circumsporozoite protein of Plasmodium falciparum in an endemic area and their relationship to resistance against malaria infection. Transactions of the Royal Society for Tropical Medicine and Hygiene 82: 827-832.

7. Roy A., Sharma V.P. \& Chauhan V.S. (1994). The use of peptide ELISA in determining malaria endemicity. Journal of Immunological Methods 167: 139-143.

8. WebsterH.K, GingrichJ.B., WongsrichanalaiC., Tulyayon S., SuvarnamaniA, Sookto P. \& Permpanich B. (1992). Circumsporozoite antibody as a seriologic marker of Plasmodium falciparum transmission. American Journal of Tropical Medicine and Hygiene 47: 489-497.

9. Ramasamy R., Ramasamy M.S., Wijesundera D.A., Dewitt I., Wijesundera A.P. de S., Pathirana S., Ranasinghe C., Srikrishnaraj KA. \& Wickremaratne C. (1992). High seasonal malaria transmission rates in the intermediate rainfall zone of Sri Lanka. Annals of Tropical Medicine and Parasitology 86: 591-600.

10. Nagendran K., Wijesundera D. A., Wijesundera A.P. de S., Ramasamy M.S. \& Ramasamy R. (1993). Malaria during the 1991-1992 Northeast monsoon season in a village in the intermediate rainfall zone of Sri Lanka. Journal of the National Science Council of Sri Lanka 21: 271-280.

11. Ramasamy R. (1987). Studies on glycoproteins in the human malaria parasite Plasmodium falciparum - identification of a myristilated $45 \mathrm{kDa}$ merozoite membrane glycoprotein. Immunology and Cell Biology 65: 419-424.

12. Ramasamy R., Nagendran K. \& Ramasamy M.S. (1995). Dynamics of the natural human antibody response to epitopes on merozoite and sporozoite surface antigens of malaria parasites. in the intermediate rainfall zone of Sri Lanka. Indian Journal of Medical Research 101: 66-74.

13. Ramasamy R., Subanesan N., Wijesundera D.A, Fernando N.K \& Ramasamy M.S. (1992). Observations on malaria patients seeking treatment in a rural and an urban area of Sri Lanka. Indian Journal of Malariology 24: 29-34.

14. Ramasamy R. (1994). Protective antigens, immune mechanisms and synthetic vaccines in malaria - 1994. Journal of the National Science Council of Sri Lanka 22(2): 93-114.

15. Del Portilo H.A, Longacre S., Khouri E. \& David P.H. (1991). Primary structure of the merozoite surface antigen 1 of Plasmodium vivax reveals sequences conserved between different Plasmodium species. Proceedings of the National . Academy of Sciences, USA. 88: 4030-4034. 